\title{
CONCEPTUAL UNDERSTANDING OF HOMEOSTASIS
}

\author{
Michal Zion, Sara Klein \\ Bar-Ilan University, School of Education, Ramat-Gan 5290001, Israel \\ E-mail: michal.zion@biu.ac.il
}

\begin{abstract}
Analyzing students' perceptions is essential to the development of studying scientific concepts. In particular, this research investigates students' conceptual understanding of a fundamental biological principle: homeostasis. Homeostasis is difficult to understand as it is both tangible and abstract. The correct perception of homeostasis is necessary to obtain a comprehensive understanding and an in-depth diagnosis of the health of the human body in a variety of physiological conditions such as aging and disease. In order to help students achieve a conceptual understanding of homeostasis, we defined the following eight characteristics: process dynamics, physiological balance, control and regulation, feedback mechanism, environments, dependency between events within a system or a process, multisystems, and levels of organization. The primary goal of this study was to investigate students' perceptions of homeostasis, after studying these characteristics. For this purpose, 93 biology majors in $12^{\text {th }}$ grade studied the characteristics of homeostasis. An analysis of the students' responses shows their correct scientific perceptions of the characteristics of homeostasis, but also reveals a great variety of erroneous perceptions. Our results suggest that the division of a scientific principle into its component characteristics may help the teachers in identifying their students' thinking and conceptual understanding of homeostasis.
\end{abstract}

Key words: Characteristics of homeostasis; Erroneous perceptions; Fundamental concept; Homeostasis; Student's perceptions. 


\section{Introduction}

\section{What is homeostasis?}

Homeostasis is a fundamental principle in many fields of biology. The scientific definition refers to the maintenance of a stable, autonomic, internal environment of the organism's body (Cannon, 1929). Homeostasis means dynamic stability of conditions, e.g., biochemical variables, such as blood glucose level, and physiological variables, such as body temperature. Homeostasis is expressed in the entire body in the regulation of organ function and enzyme activity. Moreover, it is expressed in the control of gene expression in both eukaryotic and prokaryotic organisms. It is a state as well as a continuous process, "Stability through constancy...through change" (Sterling, 2004, p. 2). Processes and stages in the life of the living organism, such as stress, disease and aging, are explained in terms of an ongoing change of homeostasis (Calabrese et al., 2006; Robertson et al., 2002; Stewart, 2006). Homeostasis is described also in plants and fungi (Cheung \& Wu, 2006; Jensen et al., 2003).

Homeostasis is relevant in many fields of biology in all levels of biological organization, from the molecular level to the entire body level. Some fields, such as physiology, consider homeostasis on the macro level. Other fields, such as hematology, endocrinology and microbiology, consider the cellular micro level - cell biology. Other fields, such as biochemistry, genetics and biotechnology, consider the molecular micro level. In the field of ecology, the concept of homeostasis is borrowed to describe the dynamic stability of populations in habitats.

\section{Developing scientific perceptions of homeostasis}

As homeostasis is a fundamental principle in biology, our aim is to forge a coherent scientific perception of homeostasis among high school students. Understanding homeostasis is fundamental to understanding the function of the body as a whole, as the organism undergoes change and development throughout its life (NRC, 2012). Proper perceptions of the different characteristics of homeostasis combine to become an updated view of homeostasis as dynamic and changing (Sterling, 2004; Stewart, 2006; Yates, 2008). In our research, we have made a meticulous analysis of high school students' perceptions regarding homeostasis in order to reveal erroneous perceptions and uproot them in a way by which a new proper knowledge can emerge. 


\section{Difficulties in learning and understanding homeostasis}

Homeostasis is both difficult to teach and to understand because it is an example of a complex, abstract system, and requires system thinking skills at the level of formal reasoning (Boersma, Waarlo \& Klaassen, 2011; Tripto, Ben-Zvi Assaraf, \& Amit, 2013; Verhoeff, 2003;). System thinking can be viewed in four dimensions: network (thinking in feedback loops), dynamic (the ability to consider dimensions of time), models (the ability to describe the system through a model, with all its components and interrelationships) and process (the ability to understand how the system regulates activity) (Ben-Zvi Assaraf, Dodick \& Tripto, 2013; Riess \& Mischo, 2010). Furthermore, the physiological systems where homeostasis can be observed in the body are complex in both form and function (for example: the urinary, the respiratory and the cardiovascular systems). Memorizing component terminology is not enough to comprehend the whole system (Hmelo-Silver \& Azevedo, 2006).

Difficulties specific to homeostasis are as followed: understanding that equilibrium (a term associated with homeostasis) is a dynamic state (Jacobson \& Wilensky, 2006); understanding ongoing complex phenomena in the body, such as thermoregulation (Buddingh, 1996); the human body is perceived as a whole, an obscure black box; understanding that different phenomena occur simultaneously; understanding that a process occurs in the body throughout the entire lifetime; understanding the cause and effect relationship between stages in a process; understanding that homeostasis is both a state and a process; Understanding processes that are abstract and unseen (such as cellular respiration, provable in the laboratory, but not physically tangible in the body); understanding control and negative feedback mechanisms (in the regulation of body temperature, for instance); understanding many terms which emerge from the description and definition of the homeostatic mechanism, such as: regulation, coordination, control, negative feedback, dynamic equilibrium, stability and internal environments; understanding terms on different organizational levels. Some phenomena are easier to comprehend on the entire body level, but are more difficult to realize at the cellular or molecular levels.

It is difficult to understand that internal contradictions are embedded in the definition and description of homeostasis: The term dynamic stability (how can a constant state change?) and maintaining a constant internal environment as opposed to dynamic equilibrium. In addition, it is difficult to understand homeostasis through its different levels of organization: some phenomena are easier to understand on the level of the entire body, but 
difficult to understand on a cellular or molecular level. The difficulty is to find a common concept that relates to different levels of organization, from macro to micro (from enzyme to heart function homeostasis), or vice versa, from macro to micro (e.g. from the balance of blood sugar to cell membrane homeostasis) (Dreifus \& Jungwirth, 1990). These difficulties might encourage the promotion of existing erroneous perceptions among students, or even cause the development of new erroneous notions.

\section{Scientific and erroneous perceptions}

The perception of a principle is individual, as it "indicates individuals' different ways of thinking about a particular grouping" (Larsson \& Hallden, 2010, p. 644). How true a perception is, can be measured by how close it is to expert opinion on the subject, in this case, scientists' opinions (Chiou \& Anderson, 2009; diSessa \& Sherin, 1998). Initial (naive) perceptions are formed by the student's experience with the principle, as well as presuppositions and theories the student has formed. These perceptions also direct the conceptual change which develops in the student as he continues to study the principle.

Two types of erroneous perceptions can be described: specific and localized focusing on details and general and inclusive. Erroneous perceptions of both types are deeply rooted in the student's cognition and world view. Preconceptions and erroneous perceptions are often considered inhibitors of conceptual change required to achieve a proper understanding of a principle ((Duit \& Treagust, 2003; Groves \& Pugh, 2002; Pelaez et al., 2005; Songer \& Mintzes, 1994).

Westbrook $(1987,1992)$ characterized erroneous perceptions following her study on perceptions of homeostasis: A. Students arrive at school with a worldview based on their experience and judgment. These perceptions are deeply rooted, stubborn and difficult to change (see also Nazario et al., 2002). B. Erroneous perceptions occur at every age level and at every cognitive level. C. Erroneous perceptions stem from inaccurate information available through different sources. D. Erroneous perceptions stem from a gap between the student's cognitive level and the level required for the student to understand the principle. E. The student's acquisition of scientific vocabulary during courses, without a thorough understanding and application results in confusion and contradiction with previous knowledge. I. In-class learning does not usually alter erroneous perceptions. 
Beginning in the 1990s, alongside research aimed at revealing and characterizing erroneous perceptions, a positive approach emerged: the identification of certain preconceptions as a means to reorganizing knowledge and reinterpreting principles (Larkin, 2012; Leonard et al., 2014). This approach opened new opportunities for understanding principles in a new and different way. Known as anchoring conceptions, they facilitate learning by serving as resources for learning scientific principles (Hamza \& Wickman, 2008, p. 143). DiSessa and Sherin (1998) also showed that students successfully employed their preconceptions as a lever to boost their progress in acquiring scientific principles in physics. Revealing preconceptions and erroneous perceptions of a certain principle among students helps us understand how students perceive this principle. The better we understand the development of a student's conceptual understanding of a principle (or idea), the more efficient we become in facilitating the development of the proper and scientific perception of that principle (Chi, 2008; Maskiewicz \& Lineback, 2013).

A detailed description of the characteristics of a subject in teaching can help teachers analyze student perceptions and pinpoint the perceptual difficulties hindering their understanding of the subject. When students learn by this approach, they can develop an extensive, in-depth perception of the subject, becoming consciously aware of the many aspects of it. A research dealing with learning evolutionary developmental biology is an example of this approach (Hiatt et al., 2013). This research examined how students learn developmental aspects of evolution (Evo Devo). The study suggests categorization of the concepts which are essential for deep understanding of developmental evolution. The categorization is hierarchical: from specific core concepts through supportive concepts from evolution and developmental biology to foundational concepts, which are fundamental concepts from all fields of biology that provide an integrative framework for the entire subject. Furthermore, teaching subjects by their hierarchical concepts helped educators address students' specific conceptual difficulties. Likewise, identifying and characterizing students' difficulties according to categories of conceptions can help in in coping with and uprooting erroneous conceptions (Hiatt et al., 2013).

\section{Research concerning perceptions of biological systems}

Many studies concerned with the understanding of biological-physiological systems that are associated with homeostasis were conducted with high school students as research participants and a few college biology students. Studies included: blood pressure control 
(Faber, 1996), blood sugar regulation (Summers et al., 1996), blood flow through the body (Harvey \& Sparks, 1999), stress (Belloni, 1999; Prewitt, 1999), and the cardiovascular system (Rodenbaugh et al., 1999). These studies examined separately students' basic knowledge about body parts and their comprehension of physiological processes. The studies did not investigate the comprehension of process dynamism and the systemic approach of each process and its effect on the whole body. Erroneous perceptions were found among high school students as well as among novice teachers.

These studies did not analyze perceptions segmentally. Such analysis would have helped map and isolate the problems encountered by students as they learn different subjects. In studies examining photosynthesis, and especially in those examining genetics, cell division (mitosis and meiosis) perceptions were categorized, enabling educators to draw a picture of students' perceptions. In Cepni's (2006) research concerning photosynthesis, the perceptions were divided into outlines: the global advantage of photosynthesis, the equations of the process of photosynthesis, plant respiration, the equations of the process of respiration, plant food, plant nutrition, plant energy sources and human energy sources. Another example is research concerning the understanding of cell division (Reimeier \& Gropengeber, 2008). The erroneous perceptions were expressed in the students' answers. Based on their erroneous perceptions, students defined mitosis as: cell multiplication, a drop in chromosome count, or enlargement of the cell nucleus. Using these definitions, students' perceptions were categorized according to: cell, nucleus, and chromosome levels. This example shows that the mapping of perceptions occurs by a thorough analysis that can serve as a basis for curriculum planning and teaching. The curriculum can be designed to tackle erroneous perceptions with great precision and root them out. Our current research divides homeostasis into characteristics which were used to examine students' perceptions. The division into characteristics can help reveal fragmentary knowledge regarding homeostasis, which may be held by the students. The fragmentary knowledge of science ideas possessed by students may represent 'alternative conceptions' or 'phenomenological primitives' (p-primes) which are either 'intuitive', or 'na"1ve', or spontaneous and transient" (diSessa, 1988, 1993, in: Leonard et al., 2014). Moreover, analysis of the students' answers will raise finer resolution subcharacteristics, allowing a broader articulation of homeostasis. 


\section{Characteristics of homeostasis}

As explained above, due to the complexity of homeostasis, we decided to break it down into eight characteristics (Authors, in press). The breakdown into characteristics can also assist in understanding homeostasis in both abstract and concrete terms. We defined the characteristics of homeostasis, based on the following terms: process dynamics (dynamism and physiological balance), biochemical-physiological mechanisms (regulation and control, and feedback,) location (environments), complex systems (dependency between events and multisystem), and occurrence on different levels in living organisms, including prokaryotes (levels of organization).

Based on the characteristics of homeostasis and on the literature review we raised the following research objectives:

1. Identifying correct and erroneous perceptions of homeostasis by its characteristics

2. Classification of students' responses regarding the characteristics of homeostasis and quantification of the percentage of erroneous perceptions.

\section{Methods}

\section{Research population}

In order to examine the perception of homeostasis among high school students, 93 Israeli $12^{\text {th }}$ graders (17-18 years old) majoring in biology participated in the study. The students were chosen from regional and urban high schools of heterogeneous populations and similar socioeconomic backgrounds. Students participated in the research with the teachers' consent, and with the teachers' interest in analyzing their students' knowledge and perceptions. Students majoring in biology at $12^{\text {th }}$ grade are at the conclusion of a three-year program for learning homeostasis, according to the national biology syllabus. Homeostasis is studied in high school as follows: In $10^{\text {th }}$ grade, the students study the biology of the human body, emphasizing homeostasis and different systems which are responsible for proper body functioning (e.g. homeostasis in macro level); In $11^{\text {th }}$ grade, the students study selected topics in biology, such as the transport system, nutrition in plants and animals, and control and regulation; In $12^{\text {th }}$ grade, the students specialize towards matriculation in selected topics, such as genetics, microorganisms, reproduction, nutrition, transport system, etc. Thus, homeostasis is studied in the context of the chosen topics. Examples are: Homeostasis of biochemical or physiological parameters, such as blood pressure, heart rate, blood osmolarity, 
and homeostasis in molecular level, as expressed in genetic control in prokaryotes and eukaryotic cells. Research participants were $12^{\text {th }}$ grade biology majors. We think that $12^{\text {th }}$ graders have well-established knowledge of homeostasis, so we can investigate their perceptions.

\section{Teaching process}

The $12^{\text {th }}$ grade student participants studied homeostasis as demonstrated in the lactose operon by means of an instructional Internet website, Homeostasis on the Molecular Level (www.hs.ph.biu.ac.il/). The website contains several learning tools: dynamic simulations, analogies, virtual labs and a game. Through these tools, the website illuminated the characteristics of homeostasis in the lactose operon, at the molecular level.

Three stages specified below made up the learning process, as follows:

\section{A. Homeostasis overview}

The teacher presented the fundamental principle homeostasis and mentioned its connection to material studied earlier, in $10^{\text {th }}$ grade. The class then practiced a jigsaw method of group learning by examples of homeostasis in the entire organism. The examples used were taken from the Moment for Thought activities appearing in the "Principles of Homeostasis" chapter on the website. Each example represented characteristics of homeostasis. Each group then discussed a different example and presented it, emphasizing the related characteristics of homeostasis. Gradually, all of the characteristics of homeostasis were listed on the board. The discussion in class revolved around generalizations: finding characteristics that are common to all of the examples learned in the context of homeostasis.

\section{B. Computer based learning of the operon subject, supported by practical tasks (eight lessons)}

The subject was taught in the context of genetics - specifically regulation of gene expression. Textbooks were used for preliminary learning. There was further elaboration upon the subject of gene expression regulation in the specific context of the bacterial operon model. The learning was guided, networked and emphasized the connection of the operon model to the idea of homeostasis. Independent or cooperative learning in pairs was also part of the process. The students were given instructional activity sheets for the four learning tools: scientific animation, animation with a smile (analog), 'scale game' (interactive) and virtual lab. In the instructional sheets the students were asked to analyze the operon model, drawing conclusions about it and about its connection to homeostasis. Before the activity for each 
learning tool, the teacher provided an introduction to the activity, with background on the content and how it relates to homeostasis. During the computer based activity, the teacher was present, to ensure students understood the instructions. Following these activities, the students carried out additional learning tasks found on the website.

\section{Homeostasis on macro and micro levels - a conclusion}

Throughout the teaching process the characteristics of homeostasis were demonstrated and highlighted in other physiological-homeostatic situations and regulation processes. These processes include physical exercise, the regulation of body temperature, the regulation of metabolic rate, and the regulation of saliva secretion. In summary, the characteristics of homeostasis were demonstrated in various animals, including snakes, elephants, and shrews, in comparison to humans. Finally, the teacher recapped the subject by explicitly linking homeostasis and the operon. Homeostasis characteristics represented in the operon were emphasized, the operon being an example of a sequence regulating gene expression and a homeostatic mechanism in bacteria, maintaining energy balance in the bacterial cell. This helps students develop an integrated view of the macro and the micro levels.

\section{Research Tools}

Questionnaires and interviews were used to examine and define student perceptions.

\section{(CHCQ) Conceptions of Homeostasis Characteristics Questionnaire}

(CHCQ) Conceptions of Homeostasis Characteristics Questionnaire was administered before and after the intervention. The questionnaire, distributed to high school students, was composed of 29 questions referring to the eight characteristics of homeostasis: dynamics of a homeostatic process, physiological balance, control and regulation, feedback mechanisms, environments, dependency between events, multisystem, and levels of organization (Table 1). The characteristics of homeostasis are presented in the questionnaire by exemplary phenomena and processes which occur on different levels of organization. The CHCQ homeostasis questionnaire comprises several types of questions: open-ended and open questions referring to images, statements and graphs. Great emphasis was given to the students' explanations of the open answers, as these reveal student perceptions. The questionnaire was reviewed by seven teachers and experts of biology and science education (four of whom hold $\mathrm{PhDs}$ ). The examiners were in agreement on average in $85.2 \%$ of the cases. The Cronbach's alpha of the questionnaire was 0.619 . 
Table 1. Contents of Comprehension of Homeostasis Characteristics Questionnaire (CHCQ)

\begin{tabular}{|c|c|}
\hline Content group & Description of Contents \\
\hline \multirow{3}{*}{$\begin{array}{l}\text { Dynamics of a } \\
\text { homeostatic process }\end{array}$} & Understanding homeostasis as an ongoing, continuous process \\
\hline & Understanding homeostasis: Correcting fluctuations \\
\hline & $\begin{array}{l}\text { Comprehending the dynamics of homeostasis: Immobility or } \\
\text { motility, dynamism, directionality, constancy, and cyclicality }\end{array}$ \\
\hline \multirow{3}{*}{ Physiological balance } & Understanding homeostasis: Does homeostasis mean equilibrium? \\
\hline & Understanding homeostasis: Correcting fluctuations. \\
\hline & $\begin{array}{l}\text { Understanding homeostasis: Formation of different levels of } \\
\text { homeostasis throughout the lifespan of an organism }\end{array}$ \\
\hline \multirow{2}{*}{$\begin{array}{l}\text { Control and regulation } \\
\text { of a homeostatic } \\
\text { process }\end{array}$} & $\begin{array}{l}\text { Understanding homeostasis: Control, regulation, efficiency of a } \\
\text { homeostatic process }\end{array}$ \\
\hline & Distinguishing and associating between homeostasis and feedback \\
\hline Feedback mechanism & $\begin{array}{l}\text { Identifying and understanding the mechanism of negative or } \\
\text { positive feedback }\end{array}$ \\
\hline $\begin{array}{l}\text { Relationship between } \\
\text { the internal and } \\
\text { external environments }\end{array}$ & $\begin{array}{l}\text { Understanding homeostasis as a reciprocal relationship between } \\
\text { environments }\end{array}$ \\
\hline $\begin{array}{l}\text { Dependency between } \\
\text { events within a system } \\
\text { or process }\end{array}$ & $\begin{array}{l}\text { Mutual dependence among events within a single process over } \\
\text { time }\end{array}$ \\
\hline \multirow{3}{*}{$\begin{array}{l}\text { Multisystem (Complex } \\
\text { system) }\end{array}$} & $\begin{array}{l}\text { Understanding homeostasis as a multisystem phenomenon: } \\
\text { Communication and coordination between systems, processes } \\
\text { occurring simultaneously. }\end{array}$ \\
\hline & $\begin{array}{l}\text { Identifying and understanding homeostasis in the body as a whole, } \\
\text { in anomalous or extreme conditions }\end{array}$ \\
\hline & $\begin{array}{l}\text { Homeostasis occurs in different organisms (poikilothermic as } \\
\text { well as homoeothermic) }\end{array}$ \\
\hline \multirow{2}{*}{ Levels of organization } & Molecular-level homeostasis in the whole body \\
\hline & Molecular-level homeostasis in bacteria \\
\hline
\end{tabular}




\section{Interviews}

A total of 15 students were interviewed. The personal interviews were semi-structured and conducted both in writing and orally. The interviews were comprised of content questions. The goal of the interview was to identify and thoroughly examine personal perceptions of the biological topic during a free conversation with the student (White, 1988). Four types of knowledge of homeostasis were contained in the questionnaire: declarative -define homeostasis, procedural - draw a graph to describe your heart rate, analogical -draw homeostasis or choose images best describing homeostasis and explain your choice, and conceptual -notice the two circles, one marked feedback, the other homeostasis. How would you arrange them: next to each other, one on top of the other, or one inside the other?"

Content questions can be categorized into three types as the following:

A. Descriptive: 1. Questions requiring examples- Give an example of homeostasis; 2. Experience questions- In a sitting position- is your body in homeostasis?; 3. Focused descriptive questions- Draw your body temperature for three hours during normal activity.

B. Comparative: Does homeostasis of the glucose level (micro) resemble homeostasis of body temperature (macro)? How would you complete a description of the relationship between homeostasis and feedback? Homeostasis is... and feedback is....

C. Stimulating: Why did you draw a fluctuating graph for heart rate, and a straight graph for body temperature?

\section{Data analysis}

Students' responses to open-ended questions on the questionnaire were content analyzed by the categories of homeostasis. We examined the prevalence of the characteristics of homeostasis represented in students' responses. For instance, in the case of the internal and external environment: Do the students always, often, rarely, or never refer to homeostasis in the context of internal and external environments? Students' perceptions regarding the characteristics of homeostasis were classified into four levels: High - full and adequate responses; Medium - correct but partial responses; Medium-low - partially correct responses; Low - erroneous responses. Table 2 represents an example for the analysis. The analysis enabled us to quantify the percentage of students responding at each level. The interviews were referenced to reinforce our analysis of the validity of student perceptions expressed in the questionnaire. 
Table 2. Levels of responses reflecting students' perceptions of the characteristic: feedback mechanisms

\begin{tabular}{|c|c|c|}
\hline Category & Level & Examples of perceptions of the characteristic, feedback mechanisms \\
\hline \multirow[t]{5}{*}{$\begin{array}{l}\text { Activity of } \\
\text { ADH hormone }\end{array}$} & $\begin{array}{l}\text { High } \\
\text { Identifying } \\
\text { process as } \\
\text { a negative } \\
\text { feedback }\end{array}$ & $\begin{array}{l}\text { (1) "Due to the decrease in water, ADH secretion is increased, followed by a reduction in urine and a } \\
\text { decrease in ADH. The hormone brought about an action that caused its own quantity to diminish." } \\
\text { (Or1) } \\
\text { (2) "This is an example of negative feedback because the reaction to the reduction in the volume of } \\
\text { urine was the decrease in the ADH level. This is a return to the previous state." (Shir1) }\end{array}$ \\
\hline & $\begin{array}{l}\text { Medium-low } \\
\text { Negative feedback is a } \\
\text { decrease in factor, a }\end{array}$ & $\begin{array}{l}\text { (3) "According to the description, there is a process of ADH being created and then the ADH level } \\
\text { decreases. So this is an example of a negative feedback." (Gai1) } \\
\text { (4) "Because something negatively affects something else. Decreases it, depletes its concentration. }\end{array}$ \\
\hline & $\begin{array}{l}\text { Negative feedback is a } \\
\text { negative thing }\end{array}$ & $\begin{array}{l}\text { (5) "At the end of the process there's something negative affecting the body, compared to the } \\
\text { beginning of the process." (Ayl1) }\end{array}$ \\
\hline & & $\begin{array}{l}\text { (6) "The decrease in water eventually causes a decrease in the ADH level, and this are therefore } \\
\text { positive feedback, distancing from the constant value." }(\mathrm{Br} 1)\end{array}$ \\
\hline & $\begin{array}{l}\text { Positive feedback - a } \\
\text { direct increase response }\end{array}$ & $\begin{array}{l}\text { (7) "The decrease in water causes an increase in ADH." (Hn1) } \\
\text { (8) "... the body works to reduce urine volume in order to maintain water. This is an example of } \\
\text { positive feedback because it is a direct reaction to the decrease in the amount of water in the } \\
\text { body." (Osher) }\end{array}$ \\
\hline $\begin{array}{l}\text { Reduction of } \\
\text { blood sugar to } \\
\text { a certain point } \\
\text { but no } \\
\text { further, } \\
\text { several hours } \\
\text { following a } \\
\text { meal }\end{array}$ & $\begin{array}{l}\text { High } \\
\text { Identifying } \\
\text { process as } \\
\text { negative } \\
\text { feedback }\end{array}$ & $\begin{array}{l}\text { (10) "Because there was a deviation in the body and the constant value of blood sugar rose, so the } \\
\text { body goes through some correctional mechanism applying the insulin hormone... that is, more } \\
\text { glucose molecules permeate the cells and blood sugar decreases. This is correction = negative } \\
\text { feedback" (Chen1). } \\
\text { (11) "Because the deviation in the blood sugar level is corrected to the constant value. This is the } \\
\text { purpose of negative feedback." (Br1) } \\
\text { (12) "Following a meal, blood sugar drops. After it goes up, it comes down, so this is negative } \\
\text { feedback." (Dani1) }\end{array}$ \\
\hline
\end{tabular}

High - full and adequate responses; Medium- correct but partial; Medium-low - partial correct; Low - erroneous responses 
Table 2 (Cont'd). Levels of responses reflecting students' perceptions of the characteristic: feedback mechanisms

\begin{tabular}{|c|c|c|}
\hline Category & Level & Examples of perceptions of the characteristic, feedback mechanisms \\
\hline \multirow{4}{*}{$\begin{array}{l}\text { Reduction } \\
\text { of blood } \\
\text { sugar to a } \\
\text { certain } \\
\text { point but } \\
\text { no further, } \\
\text { several } \\
\text { hours } \\
\text { following a } \\
\text { meal }\end{array}$} & $\begin{array}{l}\text { Medium-low } \\
\text { Negative feedback: } \\
\text { decrease in factor, } \\
\text { reduction }\end{array}$ & $\begin{array}{l}\text { (13) "The blood sugar decreased to a certain level and stopped. There was suppression - so it is an example of a } \\
\text { negative feedback." (Shir1) } \\
\text { (14) "As a result of an increase in blood sugar, a mechanism went into effect to decrease the concentration in the } \\
\text { blood by transferring glucose to cells. When blood sugar decreased, this mechanism ceased. This is an } \\
\text { example of a negative feedback." (Ad1) } \\
\text { (15) "The body breaks down glucose surplus and maintains the stable, desired glucose level." (Nof1) } \\
\text { (16) "Glucose only decreases, never increases, so this is negative feedback." (Ina1) }\end{array}$ \\
\hline & $\begin{array}{l}\text { The process described in } \\
\text { statement is an example } \\
\text { of positive feedback }\end{array}$ & $\begin{array}{l}\text { (17) "Following the rise in glucose concentration, the activity of the mechanism storing glucose in the cells was } \\
\text { increased. Glucose was inserted into the cells until its concentration in the blood returned to its normal } \\
\text { value. The mechanism ceased when the system went back to homeostasis." (Hds1) } \\
\text { (18) "Because there are too many carbohydrates in the body, it begins to remove the surplus, in order to keep the } \\
\text { quantity even. The body encourages glucose excretion. This is an example of a positive feedback." (Vic1) }\end{array}$ \\
\hline & $\begin{array}{l}\text { Positive feedback - a } \\
\text { direct increase }\end{array}$ & $\begin{array}{l}\text { (19) "Sugar must remain in the blood because we cannot properly function without it... we all require energy } \\
\text { throughout life." (Hil1) } \\
\text { (20) "An intensified increase in blood sugar leads to an intensified secretion of the hormone enabling greater } \\
\text { penetration of glucose into the cells - and a drop in blood sugar." (Yam1) }\end{array}$ \\
\hline & $\begin{array}{l}\text { Referring to feedback as } \\
\text { some sort of change - } \\
\text { referring to result and } \\
\text { not to mechanism or } \\
\text { process / no association } \\
\text { between feedback and } \\
\text { homeostasis / no } \\
\text { feedback in creating a } \\
\text { norm }\end{array}$ & $\begin{array}{l}\text { (21) "The end of the process does not affect its beginning and therefore there is no feedback in this case" (Hil1). } \\
\text { (22) "No feedback. This (the decrease in blood sugar level) is not a process." (Alb1) } \\
\text { (23) "Blood sugar levels decrease to a certain point but no further. No feedback. There's a homeostatic factor } \\
\text { responsible for it." (Mor1) } \\
\text { (24) "No feedback because this is a homeostatic system." (Avd1) } \\
\text { (25) "This maintains a stable internal environment - homeostasis. There is no feedback involved" (Ron1). } \\
\text { (26) "There are no stimuli and no environmental conditions." (LI1) } \\
\text { (27) "The condition has not changed so there is no need to activate any mechanism into operation. Therefore this } \\
\text { is neither negative nor positive feedback." (Hdr1) }\end{array}$ \\
\hline
\end{tabular}




\section{Results}

Before and after the learning, we found similar categories of perceptions about four characteristics of homeostasis: dynamics of a homeostatic process, feedback mechanism, environments and multisystem. There was a difference in the percentage of scientific, partial and erroneous perceptions for these characteristics following the intervention. For three characteristics -dynamics, feedback and environments - we saw an increase in scientific perceptions (full, accurate responses) after learning. However, for the multisystem characteristic a decrease was evident in the percentage of scientific responses after the learning (36\% compared to $45 \%$ ), and an increase in the percentage of erroneous perceptions (37.2\% compared to $4.9 \%$ ). Percentages of perceptions at different levels, before and after learning, are presented in Table 3. The section below specifies principle perceptions of characteristics after the learning.

\section{Findings regarding students' perceptions of the characteristics of homeostasis}

\section{Dynamics of a homeostatic process}

The dynamics of a homeostatic process are expressed in several attributes: stability, dynamism (ceaseless continuous activity), constancy (during lifetime), directionality, and fluctuations. Dynamics were examined by reference to two homeostatic parameters: heart rate and body temperature - during normal activity, over time and during alternating states of exertion and rest. Do students perceive homeostasis as ongoing dynamic processes occurring in the body? How do they draw a graph to describe their heart rate over time? How do they draw a graph to describe their body temperature over time? Students' perceptions could be extracted from their answers. (Students were asked to choose the appropriate graph and explain their choice.) Correct perceptions of the dynamics of homeostasis could be summarized thus: an ongoing homeostatic process designed to achieve an active stability of the internal environment; deviation corrections occur in the body constantly; homeostasis is a bidirectional process; homeostasis is a complex system.

Within the students' responses, we could also categorize perceptions partially or entirely erroneous - specifically related to heart rate or body temperature, or generally related to homeostasis. The following are some typical erroneous perceptions: both heart rate and body temperature are constant; heart rate is homeostatic while body temperature is constant; 
Table 3. Levels of understanding characteristics of homeostasis after learning (Percentages of N=93)

\begin{tabular}{|c|c|c|c|c|c|c|}
\hline \multirow{2}{*}{$\begin{array}{l}\text { Characteristics of } \\
\text { Homeostasis }\end{array}$} & \multirow[t]{2}{*}{ Category } & \multicolumn{4}{|c|}{ Level of understanding } & \multirow{2}{*}{$\begin{array}{l}\text { No } \\
\text { answer }\end{array}$} \\
\hline & & High & Medium & Med-low & Low & \\
\hline \multicolumn{7}{|c|}{ Dynamics of homeostatic process } \\
\hline & General & $\begin{array}{l}57.6 \% \\
(21.5 \%)^{1} \\
\end{array}$ & $(30.4 \%)$ & $\begin{array}{l}19.0 \% \\
(4.7 \%)\end{array}$ & $\begin{array}{l}12.9 \% \\
(17.7 \%)\end{array}$ & $\begin{array}{l}9.7 \% \\
(25.5 \%)\end{array}$ \\
\hline & Heart rate over time & $95.7 \%$ & & & $3.3 \%$ & $1.1 \%$ \\
\hline & Body temperature over time & $90.3 \%$ & & & $8.6 \%$ & $1.1 \%$ \\
\hline & Constancy of heart rate and body temperature over time & & $10.6 \%$ & & $1.2 \%$ & \\
\hline \multicolumn{7}{|l|}{ Physiological balance } \\
\hline & Is physical balance an expression of homeostasis? & $67.4 \%$ & & $1.5 \%$ & $29.2 \%$ & $2.2 \%$ \\
\hline & Dynamic equilibrium in an ecosystem (Is it homeostasis?) & $46.0 \%$ & & $34.8 \%$ & $6.7 \%$ & $12.4 \%$ \\
\hline \multicolumn{7}{|c|}{ Regulation Control } \\
\hline \multicolumn{7}{|c|}{ A. Homeostatic systems that dynamically stabilize a homeostatic parameter } \\
\hline & Blood clotting & $46.0 \%$ & & $38.2 \%$ & $15.7 \%$ & \\
\hline & Different quantity of mitochondria in different types of cells & $41.6 \%$ & $1.1 \%$ & & $51.7 \%$ & $5.6 \%$ \\
\hline & Stomata activity in plants & $76.4 \%$ & & $9.0 \%$ & $8.9 \%$ & $4.5 \%$ \\
\hline & Balance of iron level in the body & $62.8 \%$ & & $24.5 \%$ & $10.2 \%$ & $2.6 \%$ \\
\hline & Lactose operon activity in bacteria & $20.3 \%$ & & $75.7 \%$ & $1.4 \%$ & $2.7 \%$ \\
\hline \multicolumn{7}{|c|}{$\begin{array}{l}\text { B. Understanding behavior and change of process rate over time, throughout a living organism's lifespan - formation of a new level of } \\
\text { homeostasis (rheostasis) }\end{array}$} \\
\hline & Respiration rate throughout life & $50.6 \%$ & $15.7 \%$ & & $28.1 \%$ & $5.6 \%$ \\
\hline \multicolumn{7}{|c|}{\begin{tabular}{l|l|l|l|l|l|l|l|} 
C. Understanding of homeostatic changing throughout the lifespan of a living organism (human): Formation of different levels of homeostasis \\
Aging (Blood composition in a young and old person)
\end{tabular}} \\
\hline & Aging (Blood composition in a young and old person) & $29.4 \%$ & $11.8 \%$ & & $58.9 \%$ & \\
\hline
\end{tabular}

1 Percentages in parentheses indicate the percentages found prior to the intervention. 
Table 3 (Cont'd). Levels of understanding characteristics of homeostasis after learning (Percentages of N=93)

\begin{tabular}{|c|c|c|c|c|c|c|}
\hline \multirow{2}{*}{$\begin{array}{l}\text { Characteristics of } \\
\text { Homeostasis }\end{array}$} & \multirow[t]{2}{*}{ Category } & \multicolumn{4}{|c|}{ Level of understanding } & \multirow[t]{2}{*}{ No answer } \\
\hline & & High & Medium & $\begin{array}{l}\text { Medium- } \\
\text { low }\end{array}$ & Low & \\
\hline \multicolumn{7}{|l|}{ Feedback mechanism } \\
\hline & Reduction of body temperature after sweating & $(33.3 \%)$ & $(37.3 \%)$ & & $(8.9 \%)$ & $(20.6 \%)$ \\
\hline & Drinking suppresses thirst & $(25.5 \%)$ & $(21.5 \%)$ & & $(21.7 \%)$ & $(31.4 \%)$ \\
\hline & Activity of ADH hormone & $41.9 \%$ & & $27.0 \%$ & $21.5 \%$ & $6.8 \%$ \\
\hline & $\begin{array}{l}\text { Reduction of blood sugar to a certain point but no further, several } \\
\text { hours following a meal }\end{array}$ & $20.4 \%$ & & $32.3 \%$ & $36.6 \%$ & $9.7 \%$ \\
\hline \multicolumn{7}{|l|}{ Environments } \\
\hline & Interrelationships between internal and external environment & $\begin{array}{r}38.7 \% \\
(19.6 \%)\end{array}$ & $(56.9 \%)$ & $\begin{array}{c}36.6 \% \\
(22.5 \%)\end{array}$ & $16.2 \%$ & $\begin{array}{r}8.6 \% \\
(1.0 \%)\end{array}$ \\
\hline \multicolumn{7}{|c|}{ Dependency between events within a system or a process } \\
\hline & The dependency between heart rate and respiration & $79.8 \%$ & & $10.1 \%$ & $5.6 \%$ & $3.4 \%$ \\
\hline & Hormone secretion from hypothalamus & $47.2 \%$ & & $29.2 \%$ & $12.5 \%$ & $11.1 \%$ \\
\hline & Blood cells differentiation & $47.1 \%$ & & $11.7 \%$ & $29.4 \%$ & $11.8 \%$ \\
\hline & Cellular iron & $42.9 \%$ & & $41 \%$ & $10.6 \%$ & $4.5 \%$ \\
\hline \multicolumn{7}{|l|}{ Multisystem } \\
\hline & $\begin{array}{l}\text { The connection between two complex multisystemic factors - } \\
\text { body temperature and metabolic rate in a homeotherm and a } \\
\text { poikilotherm }\end{array}$ & $36.0 \%$ & & $19.9 \%$ & $37.2 \%$ & $6.4 \%$ \\
\hline & $\begin{array}{l}\text { Interrelations between the physiological parameters while a } \\
\text { condition of stress, in the context of homeostasis }\end{array}$ & $(45.1 \%)$ & $(38.2 \%)$ & $(1.0 \%)$ & $(4.9 \%)$ & $(10.8 \%)$ \\
\hline \multicolumn{7}{|l|}{ Levels of organization } \\
\hline & $\begin{array}{l}\text { Bacterial operon system as a homeostatic system: An example of } \\
\text { homeostasis in molecular level. }\end{array}$ & $64.6 \%$ & & $27.1 \%$ & $1.4 \%$ & $6.8 \%$ \\
\hline
\end{tabular}


body temperature is a homeostatic factor and heart rate is constant; the heart rate changes only during stress or exertion; the heart rate graph is an EKG graph; the heart rate is balanced due to homeostasis; temperature varies only during exertion; homeostasis is a change which occurs in a state of exertion; homeostasis: no change; homeostasis is a main factor for body constancy; and homeostasis is rest. Students' perceptions regarding the dynamics of homeostatic processes could also be seen in the way students analyze images.

\section{Physiological balance}

The questions regarding physiological balance focused on a separate system in some state of equilibrium. The questions were intended to examine the students' ability to distinguish between the spatial balance and dynamic equilibrium of homeostasis, which is a dynamic physiological balance. Partial or erroneous perceptions of physiological balance were characterized as follows: homeostasis is not physically balanced because homeostasis is a constant state; maintaining spatial balance is also homeostasis; dynamic equilibrium is homeostasis, regardless of the system in which it occurs.

\section{Control and regulation}

The questions about control and regulation were designed to examine the students' comprehension of this characteristic, as well as the students' ability to identify this characteristic in each system described in the questions. The answers revealed students' perceptions regarding the following systems and processes: blood clotting, mitochondria in different cells, respiration rate throughout life, activity of stomata in the plant, and aging. The body's iron reserves system and the bacterial energy system were also examined. We expected that students would be able to identify and describe the homeostatic parameter in every system that is regulated by the control system.

Some typical erroneous perceptions: defense against change is achieved physically (not by a biochemical-physiological mechanism); there is a general activity in the body that maintains a stable internal environment, or an internal equilibrium in the body; each control system is an isolated unit having nothing to do with homeostasis.

\section{Feedback mechanism}

Questions concerning feedback mechanisms emphasized the distinction between feedback and homeostasis, defining negative feedback and understanding specific feedback loops operating in the body. Partial or erroneous students' perceptions about feedback mechanisms, and about the feedback - homeostasis relationship, could be summarized as follows: negative feedback 
is a decrease in the rate of a process or of substance concentration; negative feedback is the mechanism of a negative and harmful action; positive feedback is an increase in the rate of a process or of substance concentration; positive feedback is the mechanism of a positive, efficient and important action; and feedback is change.

\section{Environments}

The characteristic environments means the relationship between the internal and external environments. This characteristic was examined by the identification of homeostasis in conditions where the internal environment resembles the external environment, as well as understanding the effects of environmental change on animals' homeostasis. The questions focused on a poikilothermic animal, thereby also examining comprehension of the universality of homeostasis: its occurrence in every living organism. Partial or erroneous perceptions concerning the interaction between the body's internal environment and the external environment could be observed more acutely in cases where change occurs in one of these environments. Some typical erroneous perceptions were characterized as follows: homeostasis is adapting the internal environment to the external environment; homeostasis is just a constant internal environment; when environments are equal, there is no need for homeostasis; homeostasis creates equality between the environments; homeostasis is needed only when environments are different; in an organism's natural environment there is no need for homeostasis; the classical relationship between environments is temperature differences.

\section{Dependency between events within a system or a process}

Each question referring to dependency between events focused on a separate system or a process comprising several events. The questions were intended to examine the students' comprehension of dependency between events in a physiological system. We classified students' perceptions of dependency between events within a system or a process. Partial or erroneous perceptions could be observed, regarding the connection of dependency between events and homeostasis. These perceptions were characterized as follows: heart and perspiration rates: the relationship between the perspiration and heart rates has nothing to do with homeostasis; hormones secreted from the hypothalamus: homeostasis and control are two independent, unconnected concepts; hormone secretion has nothing to do with homeostasis; cellular differentiation (blood cells) is a homeostatic process (no reference to the fact that differentiation is a one-way process); unlike differentiation, homeostasis means stability and constancy, while differentiation is a dynamic process. 


\section{Multisystems}

This characteristic was represented and examined in the relationship between two complex factors - body temperature and metabolic rate - in homeothermic and poikilothermic animals. Partial or erroneous perceptions were often due to failure to see a system. Some typical erroneous perceptions: there is no connection between temperature maintenance and metabolic rate; there is an internal mechanism, but this mechanism has no connection to the body's metabolic rate; metabolism depends on body temperature, but does not play a part in regulating temperature; there's an adaptation of the animal's body to its environmental conditions, but there is no connection between body temperature and metabolic rate.

\section{Levels of organization}

The questions regarding organization levels focused on homeostasis at the molecular level and the macro level in the human body and in bacteria, as well as on the macro level. These questions were designed to test the students' ability to understand a homeostatic state and process on any organization level, in any organism. We classified students' perceptions of levels of organization. Partial or erroneous perceptions reflected an understanding of micro level control and regulation but no ability to perceive the bacterial control system as homeostatic. These perceptions were characterized as follows: understanding control and regulation in a system, without identifying their homeostatic parameters; associating homeostasis directly to the relationship between environments: maintaining a stable internal environment. There was no reference to the homeostatic parameters at the micro level, e.g. a molecular system was not perceived as a homeostatic system.

\section{Findings: summary}

The findings indicate that a significant percentage of students expressed correct perceptions of the characteristics of homeostasis. The following are the major correct perceptions:

- Homeostasis is a dynamic, bidirectional process.

- Homeostasis is achieved by continuous adjustment of minor deviations.

- Homeostasis is a complex system of interconnected components.

- The similarity of environments does not contradict homeostasis. Homeostatic mechanisms maintain stable concentrations of substances and stable values for different parameters in the body's internal environment.

- Different states of homeostasis are created throughout the lifespan. 
- Homeostasis occurs at all levels of organization, and every system maintains parameters.

The following are typical erroneous perceptions found in the students' responses:

- Homeostasis is an active entity, an internal mechanism in action.

- Homeostasis is about internal and external environments.

- Homeostasis is a state of is a state of conditions kept constant, while preventing changes.

- Homeostasis simply happens because it must. It is a phenomenon to be taken for granted.

- Homeostasis is an adaption to external environments.

- Homeostasis is the maintenance of body temperature.

- Homeostasis does not occur in poikilothermic organisms.

- Homeostasis is a dynamic equilibrium.

- Homeostasis is also complementarity of structure and function.

- Changes throughout life are not homeostasis.

\section{Discussion}

By deconstructing homeostasis into several characteristics, we were able to identify both correct (scientific) perceptions of this principle and partial and erroneous perceptions, held by students. Some of these partial or erroneous perceptions are typical in reference to a single characteristic, while other perceptions refer to several characteristics. We could see that before learning, the percentage of nonscientific perceptions in the three characteristics, dynamics, feedback and environments was higher than after the learning. However, the percentage of erroneous perceptions for the multisystem characteristic was lower before than after the learning. This may be explained by the fact that the before questionnaire (pre) included a question close to the student's world for examining the multisystem characteristic a question about the connection between systems during stress. The multisystem related question in the 'after' questionnaire (post) referred to poikilothermic and homoeothermic animals - something less intuitively familiar to the student.

In perceiving the dynamics of homeostasis, students' responses expressed a different approach to heart rate and body temperature. We observed perceptions such as: heart rate is homeostatic and body temperature is constant, or the opposite. Such responses indicated a sense of pulse being the tangible reflection of heart rate, whereas minute variations of body temperature (when we are healthy) are not felt, and therefore body temperature is perceived as 
constant. We should note that contradicting perceptions were also observed: 'homeostasis is a state of rest' compared to 'homeostasis is a change in the body during exertion'. The first assumption might derive from knowledge that a healthy state is static and unchanging. The second assumption could be attributed to adhering to the classic curriculum content: the body's adaptation to a state of physical exertion or an increase in altitude as examples which explain homeostasis.

Understanding a complex system is often inhibited by adhering to preconceptions and beliefs about a certain system. One example is the notion of an invisible or a hidden control system, the structure and operation of which is totally unknown, and unnecessary to know. Students assume this control system is central, predetermined, and governs the body (Buddingh, 1996). This notion hinders the understanding that control alters in certain systems, under different conditions or through time (throughout the life-span), or that systems may be self-regulated (Jacobson \& Wilenski, 2006). The understanding of homeostasis also relies on pre-existing notions, specifically from bodily sensations and macro level perceptions of the body, with no reference to micro-level factors: small scale structures and local processes. An example of this notion was found during the current research, in the characteristic of homeostasis multisystems, pertaining to the connection between the systems which govern metabolism rate, and the systems which regulate body temperature. Many students wrote about an internal (general, obscure) mechanism operating in the body and maintaining temperature, having nothing to do with the body's metabolism rate. Another example is a reference to homeostasis as a factor which balances heart rate, or a factor which stabilizes temperature.

An essential difficulty typical to the understanding of homeostasis is the fact that it is both a state and a process. (A state is constant and a process is dynamic). Moreover, students had difficulties in understanding homeostasis, as sometimes we talk about a homeostatic factor (parameter), such as heart rate, blood glucose, body water and body energy, and at other times we refer to a homeostatic mechanism, such as blood clotting, opening and closing of stomata and hormonal regulation of body salts. Students' responses indicated that students indeed struggle in comprehending homeostasis as a process. They better understand homeostasis as a state. In the present research, we nevertheless found students who perceived homeostasis as a constant state. Some parameters were perceived as necessarily 
remaining constant, such as blood glucose. However, it appeared that a high percentage of students understood the dynamics of homeostasis: continuous correction of deviations.

There are two aspects to perceiving the dynamics of homeostasis: A. The process is incessant, meaning the ongoing, continuous correction of deviations. B. Changes in homeostasis throughout life, meaning the formation of new levels of homeostasis throughout the natural lifespan, from childhood to old age. This includes allostasis, which expresses changing conditions in the organism's outer environment, or in the body, e.g. stress and exertion (Reimann, 1996; Sterling, 2004; Stewart, 2006).

Perceiving dynamism from the ongoing and deviation correction aspect was expressed among a high percentage of students, but we also found the perception of the constancy of homeostasis. Perhaps it is easy to form a mental image of homeostasis as a dynamic, bidirectional, continuous process, when referring to a concrete biological phenomenon such as heart rate, which is dynamic by its very name. Perhaps it is more difficult to convey that image through examples such as aging, cell differentiation, or iron levels. On the other hand, understanding the changes in homeostasis through life, meaning the formation of new levels of homeostasis throughout the natural lifespan, is yet more difficult to achieve. We observed this phenomenon regarding the respiration rate in human maturation and also in aging. The perception of the formation of different levels of homeostasis is a turnabout and even a contradiction to the concept of stability in homeostasis, therefore understanding homeostasis as a multi-aspect principle requires intellectual flexibility. We observed that there is a tension between change and maintaining the status quo in homeostasis. In relation to aging, we also found the perception of homeostasis as a particular event happening to a particular person, as opposed to homeostasis changing in that person throughout his life.

Regarding the perception of homeostasis as a mechanism, we noticed that students not consider regulating systems to be homeostatic. Some students did mention the parameter maintained by blood clotting, though not as part of homeostasis; the regulation of the respiration system throughout the lifespan was not perceived a homeostatic mechanism; and the regulation of sex hormones from the hypothalamus is not homeostatic. This is also the appropriate time to mention the perceived relationship between homeostasis and feedback. On the one hand, some students viewed feedback as an indicator of homeostasis, thus concluding that if there is no feedback, there is no homeostasis. This was demonstrated in understanding the regulation of the respiration system and in understanding the hypothalamic hormone 
secretion system. However, referring to the same hormonal system, some students differentiated between homeostasis and feedback. We also noted that in the interviews, students answered correctly being asked to define the relationship between homeostasis and feedback. The students illustrated the relationship by drawing it. Perceptions of the characteristics of homeostasis were clearly expressed when images were used. This finding also occurred in research about the field of physics, regarding perceptions of heat conductivity (Chiou \& Anderson, 2009). The representation of perceptions by the use of pictorial analogy, expressed the mental image of the examined principle in the mind of the student, as Chiou and Anderson pointed out:

A mental model can be thought of as an imaginary structure that corresponds to the externally represented or perceived system in terms of the spatial arrangement of elements involved in the system and the relationships between or among these elements (Chiou \& Anderson, 2009, p. 826).

The use of images enabled students to express correct perceptions of homeostasis reflecting many aspects of the principle, as well as exposing erroneous perceptions. The correct perceptions described homeostasis as a complex, bidirectional system, with its many components interacting with each other. The erroneous perceptions viewed homeostasis as a state of rest, a constancy and a hindrance to change. Yet other erroneous perceptions pointed to homeostasis as a state of equilibrium. Moreover, other perceptions classified homeostasis as the body's reaction to exertion. Many students saw the homeostatic characteristic of environments even when there was no environment in the illustration. We noticed this when we presented students with the illustration of the sitting girl, and when we presented the computers and the wave illustration.

We interviewed students who were asked to identify characteristics of homeostasis in a variety of images. Students mentioned characteristics such as dependency between events, continuity, fluctuations, deviation correction, multisystem, environments, physiological balance, and disruption of homeostasis during illness. The present research indicates that the use of images and analogies, either in questionnaires or scientific discourses between teachers and students, stimulates students to think about the principles studied. The illustrations emphasized different aspects and characteristics of homeostasis that interact with existing knowledge previously acquired by the student, and even may reinforce this knowledge. 
One of the more prominent characteristics of homeostasis is the relationship between the external and internal environments. Various perceptions of this characteristic have been recorded, reflecting the general understanding of how a living organism functions in its environment. In addition to correct perceptions, several erroneous and contradictory perceptions stood out, especially concerning change in one of the environments. Such perceptions were: Homeostasis is the adaptation of the internal environment to the external environment. Homeostasis is the factor that causes equality between environments; when environments are similar, there is no need for homeostasis. Homeostasis is only required when environments are different. In an organism's natural environment there is no need for homeostasis. Homeostasis is required only when the external environment changes. Homeostasis is a phenomenon to be taken for granted. Homeostasis is not affected by environmental changes. These perceptions require special attention in clarifying the relationship between the internal environment of the body and the external environment surrounding it.

A prominent aspect of certain perceptions about environment was the considerable importance students attribute to temperature, even when it is not a factor of any significance in the example discussed. Take, for example, the perception that poikilotherms have no homeostasis, from which it is implied that homeostasis is the maintenance of body temperature. Further reinforcement of the position of temperature in homeostasis could be seen in a question presented to the students in the interview, asking them to draw two examples of homeostasis: $66.7 \%$ of the students mentioned body temperature as the first example of homeostasis, and an additional $11 \%$ mentioned temperature as their second example. Such a perception bears significant consequences for the comprehension of homeostasis, requiring the attention of the biology teaching community. Another phenomenon noticed in the interviews, as well as in answers to the pictorial questions, was that students saw environments in the examples, even where there were no biological environments illustrated. An extreme example was the reference to the blood clotting system, seen by students as dividing between the external and corporeal environments. Another example was blood cellular differentiation.

In conclusion, it is important to remember that our goal is to help students form a coherent scientific perception of homeostasis, so, research insights might be helpful to a wide spectrum of biology teachers. We investigated the perceptions regarding homeostasis among 
12th-grade students who had encountered this fundamental principle several times in their studies. Thus, their perceptions provide a prism of the mental models of homeostasis held by students (scientific or erroneous).

Our research suggests that deconstructing the principle discussed - homeostasis down to its characteristics, can assist in achieving this goal by two dimensions: teaching and research. Concerning teaching, the division into characteristics, accompanied by a discussion of these characteristics, illuminates the principle from every angle (Klein \& Zion, 2015). Concerning research, the division into characteristics helps clarify them for both teacher and student. By exposing teachers' and students' partial and erroneous perceptions we expect to improve our understanding of obstacles hindering the development of a principle's proper scientific perception. Discussing erroneous perceptions (such as the issue of environments) can reveal students' misconceptions so that they may be replaced by appropriate perceptions.

\section{Conclusions and implications}

Deconstructing homeostasis into its characteristics helps to clarify its attributes. In teaching homeostasis, it is important to verify that students indeed transfer perceptions of homeostasis in the field of biology between two dimensions: A. From familiar and tangible examples (such as heart rate) to other biological systems, B. From the macro-level of the entire body to the smaller scale levels of organization (the cell, the molecule) and back to the macro level. Thus, understanding homeostasis will indeed become the foundation for understanding the function and behavior of living organisms. Future research is necessary to analyze the perceptions of certain case studies and examine consistency through these students' responses regarding all characteristics of homeostasis. This follow-up will reveal whether or not students make the connection between characteristics and complete their learning with correct, coherent mental images of homeostasis. The division into characteristics can be considered a model for teaching and research into perceptions of a fundamental complex principle, either in biology or in other fields of knowledge.

\section{References}

Ben-Zvi Assaraf, R.,Dodick, J., \& Tripto. J. (2013). High school students' understanding of the human body system. Research in Science Education, 43, 33-56.

Boersma, K., Waarlo, A. J., \& Klaassen, K. (2011). The feasibility of systems thinking in biology education. Journal of Biological Education, 45(4), 190-197.Buddingh, J. (1996). Working with personal knowledge in biology classrooms on the theme of regulation and homeostasis in 
living systems. In: K. M. Fisher and M. R. Kirby (Eds.), Knowledge acquisition, organization, and use in biology (pp. 126-134). Berlin: Springer-Verlag.

Calabrese, V., Stella, A. M. G., Calvani, M., \& Butterfield, D. A. (2006). Acetylcarnitine and cellular stress response: Roles in nutritional redox homeostasis and regulation of longevity genes. Journal of Nutritional of Biochemistry, 17, 73-88.

Cannon, W. B. (1929). Organization for physiological homeostasis. Physiological Reviews 9(3), 399431.

Cepni. S, Tas E., \& Kose, S. (2006). The effects of computer-assisted material on students' cognitive levels, misconceptions and attitudes towards science. Computers \& Education, 46, 192-205.

Cheung, A. Y., \& Wu, H. M. (2006). Structural and functional compartmentalization in pollen tubes. Journal of Experimental Botany, 58(1), 75-82.

Chi, T. H. M. (2008). Three types of conceptual change: Belief revision, mental model transformation, and categorical shift. In: S. Vosniadou (Ed.), Handbook of research on conceptual change (pp. 61-82). Hillsdale, NJ: Erlbaum.

Chiou, G. L., \& Anderson, O.R. (2010). A study of undergraduate physics students' understanding of heat conduction based on mental model theory and an ontology-process analysis. Science Education, 94, (825-854).

diSessa, A. A. (1988). Knowledge in pieces. In: Constructivism in the Computer Age, ed. G Foreman and P Pufall, Mahwah, NJ: Lawrence Erlbaum, 49-70.

diSessa, A. A. (1993). Toward an epistemology of physics. Cognition Instruct, 10, 105-225.

diSessa, A. A., \& Sherin, B. L. (1998). What changes in conceptual change? International Journal of Science Education, 20(10), 1155-1191.

Dreifus, A. \& Jungwirth, E. (1990). Macro and micro about the living cell: Which explain what? In: P. L. Linjse, P. Licht, W. De Vos, and A. J. Waarlo, (Eds.), Relating macroscopic phenomena to microscopic particles, a central problem in secondary science education. Proceedings of a Seminar (pp. 107-118). Utrecht, The Netherlands.

Duit, R., \& Treagust, D. F. (2003). Conceptual change: A powerful framework for improving science teaching and learning. International Journal of Science Education, 25(6), 671-688.

Faber, J. J. (1996). Graphic format for teaching long - Term control of systemic arterial pressure. Advances in Physiology Education, 15(1), s40-s49.

Groves, F. H., \& Pugh, F. (2002). Cognitive illusions as hindrances to learning complex environmental issues. Journal of Science Education and Technology, 11, 381-390.

Hamza, K. M. \& Wickman, P. O. (2008). Describing and analyzing learning in action: An empirical study of the importance of misconceptions in learning science. Science Education, 92, 141164.

Harvey, V., \& Sparks, J. (1999). Learning the regulation of peripheral blood flow. Advances in Physiology Education, 22(1), s164-s173.

Hiatt, A., Davis, G. K., Trujillo, C., Terry, M., French, D. P., Price, R. M., \& Perez, K. E. (2013). Getting to Evo-Devo: Concepts and challenges for students learning evolutionary developmental biology. CBE - Life Science Education, 12, 494-508.

Hmelo-Silver, C. E., \& Azevedo, R. (2006). Understanding complex systems: some core challenges. The Journal of the Learning Sciences, 15(1), 53-61.

Jacobson, M. J., \& Wilenski, U. (2006). Complex systems in education: Scientific and educational importance and implications for the learning sciences. The Journal of the Learning Sciences, 15(1), 11-34.

Jensen, L. T., Ajura-Alemaji, M. \& Culotta, V. C. (2003). The Saccharomyces cerevisiae high affinity phosphate transporter encoded by PHO84 also functions in Manganese homeostasis. Journal of Biological Chemistry, 278(43), 42036-42040.Klein, S. \& Zion, M. (Accepted for publication, 2015). The characteristics of homeostasis - A new perspective on teaching a fundamental principle in biology. School Science Research.

Larkin, D. (2012). Misconceptions about "Misconceptions": Pre service secondary science teachers' views on the value and role of student ideas. Science Education, 96, 927-959.

Larsson, A., \& Hallden O. (2010). A structural view on the emergence of conception: Conceptual change as radical reconstruction of contexts. Science Education, 94, (649-0-664). 
Leonard, M. J., Kaliowski, S. T. \& Andrews, T. C. (2014). Misconceptions yesterday, today, and tomorrow. CBE - Life Science Education, 13, 179-186.

Maskiewicz, A. C., Lineback, J. E. (2013). Misconceptions Are "So Yesterday!". CBE—Life Sciences Education, 12, 352-356.

National Research Council [NRC]. (2012). A Framework for K-12 Science Education: Practices, Crosscutting Concepts, and Core Ideas. Washington, D.C.: The National Academies Press.

Nazario, G. M., Burrowers, P. A., \& Rodriguez, J. (2002). Persisting misconceptions. Journal of College Science Teaching, 31(5), 292-296.

Pelaez, N. J., Boyd, D. D., Rojas, J.B., \& Hoover, M. A. (2005). Prevalence of blood circulation misconceptions among prospective elementary teachers. Advances in Physiology Education, 29, 172-181.

Prewitt, R. L. (1999). Teaching vascular adaptation to mechanical stress. Advances in Physiology Education, 22(1), s211-s213.

Reimann, S. (1996). Homeostasis and stability. Retrieved from http://www.math.unibielefeld.de/ bibos/preprints/bibos97-773.pdf

Reimeier, T., \& Gropengeber, H. (2008). On the roots of difficulties in learning about cell division: Process-based analysis of students' conceptual development in teaching experiments. International Journal of Science Education, 30(7), 923-939.

Riess, W., \& Mischo, C. (2010). Promoting system thinking through biology lessons. International Journal of Science Education, 32(6), (705-725).

Robertson, D., Jordan, D., Jacob, J., Ketch, T., Shannon, J. R., \& Biaggioni, I. (2002). Ageing and water homeostasis. Novartis Foundation Symposia, 242, 265-278.

Rodenbaugh, D. W., Collins, H., Chen, C. Y., \& Dicarlo, S. E. (1999). Construction of model demonstrating cardiovascular principles. Advances in Physiology Education, 22(1), s67-83.

Songer, C. J. \& Mintzes, J. J. (1994). Understanding cellular respiration: An analysis of conceptual change in college biology. Journal of Research in Science Teaching, 31(6), 621-637.

Sterling, P. (2004). Principles of allostasis: Optimal design predictive regulation, pathophysiology and rational therapeutics. In: J. Schulkin, (Ed.), Allostasis, Homeostasis, and the Costs of Adaptation (pp.17-64). Cambridge University Press. Retrieved June 9, 2015, from http://www.brown.edu/Departments/Human_Development_Center/Roundtable/Sterling.pdf

Stewart, J. A. (2006). The detrimental effects of allostasis: Allostatic load as a measure of cumulative stress. Journal of Physiological Anthropology, 25(1), 133-145.

Summers, R. L., Woodward, H., Sanders, D. Y., \& Hall, J. E. (1996). Graphic analysis for the study of metabolic states. Advances in Physiology Education, 15(1), s81-s87.

Tool, G., \& Tool, S. (1995). Understanding biology (3rd ed.). Cheltenham, England: Stanley Thornes.

Tripto, J., Ben -Zvi Assaraf, R., \& Amit, M. (2013). Mapping what they know: Concept maps as an effective tool for assessing students' systems thinking. American Journal of Operations Research, 3, 245-258. Verhoeff, P. (2003). Towards systems thinking in cell biology education. Tekst. - Proefschrift Universiteit Utrecht. Retrieved June 7, 2015, from http://www.ecent.nl/servlet/supportBinaryFiles?referenceId=1 \&supportId=1471

Westbrook, S.L. (1987). A cross-age of student understanding of four biology concepts. Doctoral dissertation, University of Oklohama. (UMI No. 8804364)

Westbrook, S. L., \& Marek, E. A. (1992). A cross-age study of student understanding of the concept of homeostasis. Journal of Research in Science Teaching, 29(1), 51-61.

White, R.T. (1988). Learning Sciences (pp. 49-77). Oxford, New York: Basil Blackwell.

Yates, F. E. (2008). Homeokinetics/Homeodynamics: A physical heuristic for life and complexity. Ecological Psychology, 20, 148-179. 